\title{
LEUKOPLAKIA OF THE ANAL VERGE WITH BLEEDING HEMORRHOIDS- A CASE REPORT
}

\author{
Pravin J GuPta \\ Clinical Head \\ Nagpur, Índia
}

\section{Case Report}

On $14^{\text {th }}$ August 2002 , a 46 -year- old male, an office clerk, reported with bleeding and prolapse per rectum for since 6 months, however without any complaint of any pain, pruritus or discharge per anus..

Upon anal and intra anal examination a circumferential area of thickening and whitish discoloration of the anal verge, which was extending up to the dentate line, was found. Perianal skin was macerated, excoriated and thickened, suggestive of leukoplakia. (Figure 1) Anoscopy showed prolapsing hemorrhoids.

The patient gave no history of previous anal surgery, homosexual contact or exposure to radiation. He had been using various hemorrhoids ointments in and around the anus for the last four months. The test for HIV virus was negative.

The hemorrhoids were ablated using a Ellman radiowave generator [Ellman International Inc., Oceanside, NY, USA] under local anesthesia with the patient in a lithotomy position. A biopsy was taken from the anal verge and the patient was discharged after 2 hours. He was asked to return after 4 weeks.

The microscopic picture of the biopsied anal skin showed pronounced cornification of the anoderm. Acanthosis was prominent, but rete cells were orderly and the basal layer was well defined. The dermis showed profuse chronic inflammation, with lymphocytes, plasma cells and large mononuclear cells in the papillary layer.

At the 4 week follow-up, the patient was asymptomatic, the biopsy wound was healed and the hemorrhoids were not visible. The patient was asked to report each year or earlier if symptoms appeared. At the last follow-up in October 2007, the patient had no specific anal symptoms except occasional Dyschezia. The leukoplakic area remained unchanged.

\section{Discussion}

Leukoplakic lesions are most commonly seen in the oral cavity, more frequently in men than in women at that site. . They are somewhat less common on the vulva. The bladder, kidney pelvis, ureters, larynx, esophagus, cervix and glans penis are occasionally involved. ${ }^{1}$ Extensions of primary vulvar leukoplakic lesions with involvement of the perineum and perianal skin have been described in literature. Primary leukoplakia on the anoderm of the anal canal has been occasionally reported. The lesions developed on the so-called "mucosa" or anoderm of the anal canal, with some extension to the adjacent rectal mucosa.

Leukoplakia is considered to be a precancerous dermatosis of mucous membranes analogous to senile keratosis of exposed skin surfaces $^{2}$. Several patients with carcinoma in situ had a discrete

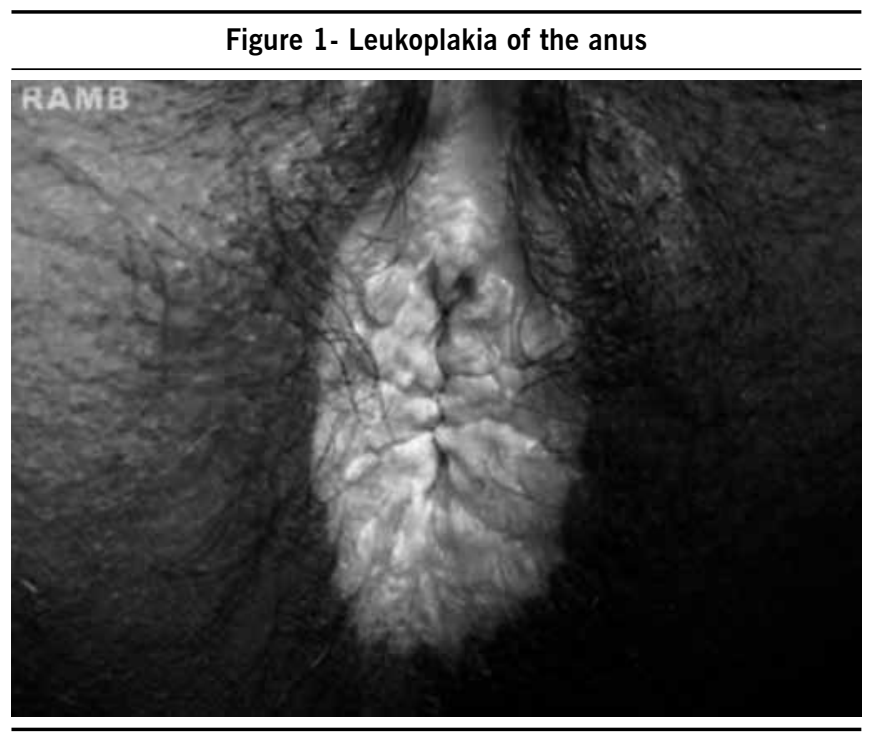

area of leukoplakia in the anal canal or a pigmented plaque of the anus and anal canal ${ }^{3}$. However, in this case, leukoplakia was absolutely innocuous with no change in the color, texture or extension of the lesion noticed over a period of five years.

The cause of leukoplakia is still controversial ${ }^{4}$. Earlier investigators indicated syphilis as a prominent factor in oral lesions. Deficiencies of vitamin $A$, hydrochloric acid, vitamin $C$ and estrogens have been mentioned as causative factors in vulvar leukoplakia. Excessive excretion of irritating organic urinary acids has also been considered ${ }^{5}$. Other investigators consider that prolonged local irritation from any cause, acting on a deficient, aging epithelium is a fundamental cause of this lesion ${ }^{6}$. The author considers that, probably, continuous use of hemorrhoids cream was the cause of leukoplakia in this patient. A correctly interpreted preliminary biopsy serves as a guide for a proper therapeutic approach.

Follow-up of our case shows little evidence that leukoplakia of the anal canal is premalignant, but patients should be followed carefully, since the natural history of this rare lesion remains unknown.

\section{References}

1. Bender MD, Lechago J. Leukoplakia of the anal canal. Am J Dig Dis. 1976;21:867-72.

2. Templeton JL, Brennen MD. Anal leukoplakia: management using a staged plastic procedure. J R Coll Surg Edinb. 1991;36:333-4. 
3. Jongen J, Reh M, Bock JU, Rabenhorst G. Perianal precancerous conditions (Bowen disease, Paget disease, Carcinoma in situ, Buschke-Lowenstein tumor) Kongressbd Dtsch Ges Chir Kongr. 2001;118:79-86.

4. Riedler L. "Bowenoid" leukoplakia in the anal region. Klin Wochenschr. $1988 ; 66: 271-3$
5. Foust RL, Dean PJ, Stoler MH, Moinuddin SM. Intraepithelial neoplasia of the anal canal in hemorrhoidal tissue: a study of 19 cases. Hum Pathol. $1991 ; 22: 528-34$.

6. Del Río M, Maturi RH, Maturi HV. Postoperative anus stricture and leukoplakia Iesions. Acta Gastroenterol Latinoam. 1987;17:337-42. 